\title{
SIBIU 2007 EUROPEAN CULTURAL CAPITAL PROGRAM: THE COMMUNICATION MANAGEMENT
}

\author{
Rotariu Ilie, senior lecturer, ilie.rotariu@ulbsibiu.ro \\ "Lucian Blaga" University of Sibiu
}

\begin{abstract}
This paper is a case study: the town of Sibiu - Transylvania - Romania. A good communication is compulsory to boost a tourist destination for the both major actors: the organizers and the population - the potential tourists. We argue that the communication is the key tool to have good results in organizing an event as The European Cultural Capital.
\end{abstract}

I shall briefly refer on the program, budget and program management. I have collected my info until August. A detailed research will be done for sure when all will be ended (an evaluation must be done for the EU in order to get its funds). Any way, I have to underline the necessity that organisers and researchers must start today to collect data from the visitors and the real life, from the participants. After the events they will have only the archives, no "test" of the shows.

The official objectives of the Programme: raising the international profile of Sibiu; long term cultural development; attracting international visitors ; enhancing feelings of pride and selfconfidence ; growing and expanding the local audience for culture ; improving social cohesion and creating an economic downstream; improving cultural and non cultural infrastructure *Developing relationships with other European cities/regions and promoting European cultural cooperation; promoting creativity and innovation are similar with those chosen by other former Cultural Capitals, as stated by Palmer Report.

A slow nuance was added by the Sibiu Mayor in August in local newspapers when saying:

* to offer a fine year to people of Sibiu

* to make Sibiu better knows

* to increase significantly the number of tourists

* to consolidate the cultural institutions and to extend the existing events

* to improve our capacity of management, mainly the cultural one

You can already notice the graceful movement from the application form requirements to the conclusions based on results.

Sibiu 2007 has followed nearly the same rules as the other towns and Luxemburg. It has settled 9 sections in order to cover the whole spectrum of the culture: architecture, urban installations; visual arts; the shows' arts; video, movies, multimedia; literature, publications; music; mobility, conferences, researches; patrimony; interdisciplinary; others

Rules were established and made public for operators that wanted to participate, to organize events or ask for financial support (see www.sibiu2007.ro). The Sibiu 2007 Association has had troubles to handle the process and to realise an equilibrium in order to have diversity. As long as I remember there were no major complaints except ASTRA Museum, mainly critics of the decisions of the Ministry of Culture. The allocations of complimentary funds offered by the County Council were more contested. At least as they were reflected by mass media. Keeping 
the balance, 2007 Sibiu Association (whose president is the Mayor Klaus Johannis) has arrived to approve and finance near 1500 events, some a tradition in Sibiu, some new or incidentally.

$\begin{array}{lclc}\text { January } & 56 \text { events } & \text { July } & 158 \text { events } \\ \text { February } & 56 \text { events } & \text { August } & 368 \text { events } \\ \text { March } & 100 \text { events } & \text { September } & 165 \text { events } \\ \text { April } & 92 \text { events } & \text { October }^{*} & 81 \text { events } \\ \text { Mai } & 166 \text { events } & \text { November }^{*} & 33 \text { events } \\ \text { June } & 145 \text { events December* } & 27 \text { events } \\ \text { Total } & 1447 \text { events } & \end{array}$

The programs organized with Luxembourg enjoyed a special attention. A lot of space was allocated for the events organised by former citizen of Sibiu living now abroad. It seams to be made in purpose in order to reinforce the ties with people in Diaspora and in this manner to increase Sibiu's exposure abroad.

Much more details on this subject can be found on sibiu2007 site and a detailed analyze will be made after the events. There is a special group of events that must be mentioned: "imported" events, in majority of national interest that were dislocated in Sibiu in 2007 to enrich the program but also to take advantage of the mass media international free promotion: I just quote the UNITER Awards Gala (for theatre), the MTV Awards Romania, George Enescu Festival or Bucharest Romania Opera show. Much more comments have raised events performed by an international cooperation like Milan Scala Orchestra or Vienna Opera, when people of Sibiu hardly arrive to get a ticket because of the large reservations made for guests and lobbyists, mainly from Bucharest.

We can nominate a distinct category of events: popular ones, free entrance either on the Tent or on the streets. The participation was large and the involvement complete, even if the public of Sibiu is a very conservative one and hard to catch. The result was amplified by the fact that the main street and the two central squares were turned into huge open restaurants that attract plenty of public. As Sibiu is short in cultural locations as closed halls that can be used during rain, or large rooms or halls to host a large number of spectators a lot of "unconventional" spaces were promoted, and so, adequate shows or events.

A detailed research on events must be carried on in order to establish which of the new ones must be promoted. Unfortunately there was made no methodological, trustful investigations to allow a comparative evaluation. The results will rely only on future deciders. Even local media have allowed few spaces for such a large number of events and they have presented only the great or distinguished ones. The evaluation's maps, requested by Sibiu 2007 Association prove always that the event was gorgeous.

\section{The budget:}

It is a subject that will be detailed analyzed in the future. I want to border on the widespread part of the financing of Sibiu 2007.

According to the official records the budget of Sibiu 2007 European Cultural Capital is of 21,404,200 EURO. This is the amount handled by Sibiu 2007 Association. It comes: 3,654,200 EURO from the Romanian Ministry of Culture, 16 millions EURO from the Local (Sibiu) Council and 1.750,000 EURO from Sibiu 2007 Association as administration and staff expenses. The EU will contribute with 0.5 million EURO at the end, after having the results of the program evaluation. In fact this money is the part dedicated to organize the events. If a little bit more than $1 \%$ will be financed by EU I am interested on the other $99 \%$. Mathematically we stay now on $2.3 \%$ to $97.7 \%$. 
If we stay only on the objectives stated by the program, like the rehabilitation of cultural infrastructure, I shall cote only ASTRA Library, Gong Theatre, Astra Museum and the information centres of the list of investment made in the town Sibiu by the Sibiu County Council with 6.4 millions of EURO. We can add Thalia Theatres finished last year that took so much money that nobody wants to remember. You have to add also the funds for normal activity that are important too. Important events are financially helped by the local public authorities by Public Private Partnership or as they are their own bodies: The County Council has allocated for 22 events (Carl Filtsch Piano Festival, Gypsies festival, Folk Festivals etc.) 0.74 millions of EURO. A closer look will find a similar situation by the Local Council.

The promotion budget of the Local Council (the Mayor House) and the county Council are not dedicated to Sibiu 2007 event. But only the AJTS (The Association for Tourism of Sibiu County) has spent during the first semester of 200733,000 EURO to participate to 8 international fairs were the main subject was compulsory Sibiu2007. We have to add the transfers made for the traditional events as International Theatre Festival, ASTRA Film Fest, Jazz Festival etc. and the amount will increase substantially. What is more surprising is the high degree of self financing of local main events by sponsorship, sells, media cooperation. I could not have a total amount, even approximated, as anyone was busy with the next event.

There still is a large part of direct funding: the national sources for national level events i.e. 1.4 million plus 0.28 million allocated by the government and the Ministry of Culture for the Ecumenical Meeting in September - as declared my the ministry of culture.

It is rather uncertain we can have a total amount in next months, even if this is a compulsory operation, if the Sibiu community wants to carry on the events for the next year. This year's events were prepared since 2005! I suppose I can say that the collateral funding has at least doubled the budget of Sibiu 2007 Association.

This was the small pie. And we have already found out that Sibiu 2007 meant a stronger effort of the local community in funding the chance EU has offered.

Romanians have a strange obsession: what Europe will say about us, about our facts? Or better formulated: we have to "face", to be at "standard" when meeting Europe, or strangers. Last major renovation of the medieval part of the town (old of 8 centuries) was in 1968-1970. Since then, practically nothing was repaired, even the maintenance works ceased during the last decades. But Sibu has to be dignified for such a trial as being the Cultural Capital of Europe...with Luxemburg! That has turned into a challenge. When Mayor Johannis has realize he can use this opportunity; huge works to rehabilitate and to modernize the town have started. And in Saxons manner: to last! Only one figure will give you the level: 135 millions only for investments in 2007 Sibiu budget. People that have visited the town some years ago will not recognized it. Natural, this money was not allocated for Sibiu 2007 event, but without these works there would be no scenery! We might add the international airport with 55 millions. And 5 hotels of $3-5 *$ that is near 1,000 beds, plus pensions, restaurants etc. etc.

We need a total for historical records, but also to create a data basis for further marketing plans. Someone must allocate the funds to carry on this work.

\section{The management:}

Management is vital for such big operations. There was no practise, no precedent in Sibiu or Romania, no events literature or special training available nearby. Luxemburg has already experienced such an event but the habitudes and mentality of Sibiu population was different. Several visits - criticized at the time - of officials of Sibiu abroad and foreign delegation in Sibiu, having as main purpose the Cultural Capital Program have gathered a minimum of information. It is the mayor that has imposed finally the principles. 
First one: to avoid any political involvement. In Romania, Romanians, more than other people worry about political influence. The experience of the first decade of democracy in Sibiu made locals more susceptible. The Mayor's FDGR is a small organisation and has no influence in Bucharest where the funds are allocated. Total neutrality might be the key for success.

Second: clear separation of the Program of the daily activity of the local power structures. An NGO: the "Association Sibiu/Hermannstadt European Capital of Culture 2007" was registered where the main institutions and local personalities join together and the Ministry of Culture delegate. To enable quickly communication with local authorities the Mayor was elected as president. The Mayor is also the leader of FDGR that enjoy the majority in the County Council and several local councils in Sibiu County that helps!

Third: the executive work was conferred to employees hired by the Sibiu 2007 Association under the direction of a manager that is also the secretary of Sibiu 2007 Association.

The principle was to leave the carrying on of the projects to the cultural operators (the events applicants and organizers). The Sibiu 2007 Association staff should hang on only on major activities: selection of the projects, supervision of the contracts, surveillance of the events and final evaluation for last payment. The rule of EU was applied: full grand is paid at the end of the events, if and when the contract requests were fulfilled. To keep control on the activity - but also because of lake of qualified or trained persons - the team was as small as possible; around a dozen by now. The start was difficult (the ATLAS Winter University project has to face it in January) because of lake of experience and because Romania just joined the EU and new rules were applied i.e. public electronic auctions using EU system, for services, eTickets, etc.

1400 events, among which we can count the International Theatre Festival with over 2,000 participants that had to be accommodated, lead, assisted etc. or Vienna Opera etc. suppose a lot of work, very diversified, asking for various skills, and large amounts of money that must be observed. The events funded or organised by the Ministry of Culture was the task of the Sibiu Council for Culture and the events funded or organised by the Local Council was the task of the House of Culture of the Town of Sibiu. The direct management and the proceedings of every event were the task of the two bodies.

In this way, any political involvement was avoided, the information flew quickly and real, the money are double controlled and checked and paid only on results, the power spited. After the hesitation of the beginning a weekly meeting of Sibiu 2007 Association on each Tuesday play the role of the headquarter of the program, and information and decisions are spread in due time.

I have also to point out the management efforts made by each cultural operator, the rules that were established and imposed by experience; some of them will be mentioned above.

Additional help has come from several directions. Once Palmer Report made public, during 2004 - 200617 graduation's thesis were drown up only by the students of Economics Faculty, and conference were introduced into curricula and attended by 1,700 students each year. This is only an example on how the local forces have added their expertise, information and efforts for the program.

As the project must go on the next years, I find compulsory to carry on researches on management system now, as long as the project is running and "actors" are present, in order to valorise the collected experience and identify the problems to avoid and draw a new system for further developments.

The results:

I have not analyzed the results of the European Cultural Capital. This is the subject of the evaluation of EU. I have tried to outline the "boule de neige" effect of the program and the 
collateral incidents as close as possible to the Palmer Report. The goal is to argue if Sibiu is a tourist destination and how this program has boosted it, if so.

\section{Infrastructure:}

One of the main objectives of the European Cultural Capital was the rehabilitation and the development of the cultural infrastructure. The same for Sibiu.

Sibiu enjoys one of the largest medieval areas of Europe. The cultural facilities were (and are) wide, well fitted and in function. I.e. there are several museums, three of them of national importance. Brukenthal Museum was opened 3 years before Louvre. In ' $70 \mathrm{~s}$ all of them were well organised for tourism as a collection of artefacts. Late '70 s, as an exception, ASTRA Museum (former Museum of Popular Technique - "an homage for man's brain and hand") has already turn into "experiences" space: an inn was moved in, at the entrance tourists could see movies with all technical installation working, artisans performed in situ etc. It was a prove of the quality of local cultural people. Since ' 70 no rehabilitation was made, even maintenance was an unsolved problem.

In 1968 the former region Brasov has spited into counties. Sibiu County was a kind of "elephants' cemetery" for Brasov communist nomenclatura. It was the time of huge town development in Romania. The new Sibiu leaders need nothing: no stadium, no sports hall, no theatre and no public building as they already existed. They made few requests for new investments. Except the Cultural House of Labour Union, compulsory in every town! No one thought for future!

In '90 s the infrastructure of Sibiu was in a critical position: the medieval areas near to ruin, the public buildings too, no new collections, no large hall for performances, under financing. In 1990 the first big business of the new power was to sell the apartments in the block of flats. After a couple of years reinforcement works were necessary. The majority of the streets were not asphalted.

In the same time, large quarters of private houses have kept the standard. And many cultural events have managed with the existing facilities.

This was not a problem of the Mayor, of the Local Council or local parties. It concerned the whole population. There was no leading force in spite of the votes "against" of the population. The civil society was awaked: to choose (or designate) the town as Cultural Capital was easy; to find the forces to carry on the task it was much more difficult. A lucky time has come. Johannis's team has started with two projects that lasted for years: the bridge across Cibin River and the bridge over the railways. No one could stay against. They added water supply rehabilitation (critical problem for the town) and the facilities for the Industrial Park. Those have brought jobs and prosperity when people of Romania looked to find a job abroad. And votes 4 years later, near $90 \%$ !

The rehabilitation of the cultural units was compulsory. The only one problem was to find the money, as in majority they belonged to local authorities. The local administrations have to boost the cultural facilities at international and global level: lucky, there were local people to do it! How they have found the money? I am still waiting the memories of Johannis! And those of the cultural managers too, as, in order to over cross the lake of facilities they have substituted them by "unconventional" areas; and the shows went on! New units were built: Thalia Hall, ASTRA New Library, etc. and all were rehabilitated and modernised in order to fit the new living cultural spaces.

There still remains a hole! The streets: the medieval area and the Sibiu's quarters. Sibiu has no ring: 24,000 vehicles transit the town daylily, 16,000 trucks. Try to be a house's wall for a day or too, or the owner! The "vote machine" - the new local council - started working; and the 
local architects and the civil society too. According to my information, the main effort focus on the central area and the medieval area in surrounds, in order to have the environment for the Cultural Capital. The former renovation has relied on walls. The new one focused on changing the facilities (water supping, canalisation etc. which is a more expensive work when the walls are $2 \mathrm{~m}$ large and 7 hundreds years old), and on getting underground the lines and to rehabilitate "the ambient". Inside, as private properties, the owners bear the responsibility. And they were persuaded, convinced, helped. A new furnishing concept has arisen. And "experiences" could be lived in the old town of Sibiu!

Sibiu quarters have to pay for central area. But they need restoration too, not only the transit streets. Where to find money for? The political choose has paid off. Or the chance to be designated as Cultural Capital? Or the local civil society active's existence! Any way! BERD has approved several loans, a sort of premiere in Romania. I quote two of them: one of 15 million and one of 10 million EURO: the first one to REMADE some of the main streets and squares and the second one for 3 groups of 36 streets in the quarters: changing facilities, underground the lines, new asphaltic cover, etc. Not too expensive? That is 15 EURO per year per inhabited for 10 years, or 49 EURO per year per working inhabitant for 10 years. It seams reasonable! According to Local Council data the total loans are $1.09 \%$ of the local budget. And the town have a European look, and is an adequate place for enjoying the Cultural Capital events. Methodologically, I have to prove it to you. For people living in Sibiu is common sense!

The population of the town have not waited the Mayor to work for them. There were new building even before. People of Sibiu use to be more discrete, and has avoided exhibiting themselves, as used in other areas of Romania. Walking on the streets, on the neighbourhoods, during my documentation I have found, for my pleasant surprise, a new town: each house, on each street shows a new image: either it was modernised, a new garden or at least new colours. I know for sure that there was no campaign or obligation on the matter. I have no evidence that it is a consequence of the European Cultural Capital program, but the change is simultaneous. It is a new STAND!

Last, but not the least! The town of Brasov has started to rebuilt its medieval centre early '90 s. There were no follow up. The first marry-go-round has raised many debates in Sibiu 6 years ago. Now you can find them all round Transylvania. That can not be a consequence of the globalisation: the funding was local! The large exposing on Romanian media of the preparations of Sibiu for the great event might give the idea.

To summarise: the investment in rehabilitation and new cultural facilities is only a drop compared with the ones made to build a better place to leave and visit.

\section{Social perspective:}

This is a sensitive subject: we have to settle what we put on it. We can not follow Palmer Report ideas, even the EU requests as the local environment is quite particular. The social impact is a vast question since almost all programme outcomes can be seen in social terms. Even the promotion of tourism or the creation of jobs, both common aims will be felt in the social fabric of the city.

We can not focus on minorities problems as this is not a hot subject in Sibiu. The town is the head quarter of the King and the Emperor of Gypsies all over the world. As long as the civic rules are observed - and they are - any one can proclaim himself as he wants and can be recognized by anyone who wants to. That means not that there is no problem, but it is commonly handled by all involved parts. There are poor people in Sibiu. There is plenty to do for them. The access to the events is open to anyone; there are also enough free entrances. This subject will be analyzed during evaluation and further researches. 
Unfortunately we have not the tools and the "accumulations" - the archives of regular field investigations - to can compare the evaluations. And even during this program no attention was paid to it, no application was submitted on that regard. All I can tell are just "stories", my collected information and my conclusions I have reached based on them. I am in the same position as Adam Smith or David Ricardo (I keep the proportions!) when approaching this subject. I hope that financing will be found to start.

More, the feelings of my interviewers were so different that it is hard to make an average. As a common perception I can quote that people of Sibiu are proud of living in the city and hosting the event; I have to mention my observation that local people "stand" more vertically, with reserved proud. And much more "happy". I have to approach the subject as during the ATLAS Winter University, in January, a group of students has chosen as a characterizing colour for local people the "grey", motivated by the observations made during some days that the majority of the by-passers were looking to the ground. We have discussed the subject not only in our university but also during official or unofficial meetings. It was winter, cold, but... Meantime, the main street and the two central squares host 25 terraces with near 2,000 sitting places. The streets are full of people enjoying their free time. You ca easily note the tourists for the locals; all together share the pleasure to be here.

I also noticed that Romanians have become more envy, sometimes jealously about people of Sibiu, not on a bad manner but begrudging the fact of living here and being selected. Obvious, I have no scientific evidence. My foreign readers will not believe my saying, but people of Sibiu will find it as normal by common sense. A special mention must be dedicated to people living the central area. Almost everyday, during daylight, but mainly during evening, sometimes all weekends, until midnight have to support the noise of the crowds and of the shows. And fire works! Since March at least! No complaints.

\section{Communication, promotion and media response:}

It is an other sensitive subject in spite that one of the main goals is to increase Sibiu and Romania exposure. I have found no organised records and no methodological evidences according to Western standards. The direct perception of local authorities and people involve, even people on the streets will definitely affirm that Sibiu is now well know and the relations made are large and Romania - as a country - is more known and has improved its image. How can I prove it?

The Mayor Johannis has a special gift for good communication. I have to mention the communication inside the Mayor House. A new management and a open communication has facilitated that the large number of staff has a clear vision on what is going on and are able to explain to others.

A special attention enjoys the communication with people of Sibiu. The main way was to talk directly with people involved or concerned. Comparing with the former leaders, before or after '89, Jahannis performs an open approach, a "Saxon" organisation that allows people to get simple and unrestricted access to information. The management system stimulates communication between the members and keeps in the same time the decision on one hand. Any one can have an initiative - the Mayor even use to ask for a good legal solution - and once it was adopted the one who proposed will be in charge to carry it on.

The main idea of people working in mayor House or Sibiu 2007 Association is that they are public staff and their task is to assure the success of the events they are involved to. More, they all know that they are handle public money and there for they have to pay special attention. 
There are several bodies that are in charge with the communication about Cultural Capital. Each of them on its competence: the press office of the Mayor will handle the information as the Mayor House speaker; the 2007 Sibiu Association will handle them as the body in charge with the program; the County Council press office as the county administrator; the cultural operator as the organizers a.s.o. In spite of such many sources, the information is pertinent and unitary as the management system checks it at least once a week and makes necessary corrections. Any one involved was "educated" to act free and hospitably with any one, including mass media. Everyday, the press office of the Mayor draw up a press review using around 25 newspapers. It is also true that there is little info from abroad; at least systematically collected.

The main source of news and means of promotion are the foreign visitors, official or not, that have easily access to anyone involved in the program, including the Mayor. The visits abroad are also use to promote Sibiu. For my regret I have found no "tangible" source. When asking how they can prove the opinion of their guest the reply is "I was there and I heard and saw".

We can see an explosion of good Internet sites presenting, even life, the events and the town. The organised promotion action will be analysed during evaluation; the same observation that that time will be no way to check the specific effect. Only the whole image!

\section{Tourism perspective:}

In a recent interview (August 2007) the Mayor Johannis has declared that he was disappointed by tourism leaders as there is too mach amateurism and no sectorial politic (management). He also pointed out that anyone can see that Sibiu is assaulted by tourists, many from abroad. And it is true. What show the official statistics?

Nomber of tourists in accommodation units during the first semester: $2006=60197$; $2007=75545$ that is $125.5 \%$

In Sibiu there are near 2000 places in classified accommodation units, majority hotels. When analysing the data we have found out that the average occupancy is near $40 \%$ per year. Verifying by alternative sources I have concluded that the whole system must be checked. A further research will be organised. The main problem since 1989 was to have detailed information about the tourism facilities in Sibiu. Several programs were carried on by Trier University, CHF International, AJTS, and other structures. We are in the same position. Even if several associations and structure are active on tourism field no one can have a "big picture" detailed.

When talking with actors in local tourism I realised they know the meaning of "tourism destination" and are aware they have to conjugate their efforts. But there is no public consciousness about, no motif to act. The tourism operators act selfish, on daily perspective. As long as there is a lack of offer (starting with accommodation) and enough demand to allow them reasonable profits, they have no intention to invest to organise the management of the tourist destination. The information desks (much more present and active as in other part of Romania) play between getting and offering information and supplying reservation of tourist services.

When 2007 approached, some years before there was an intensive work to find and organize a brand for the town?, for the county?, for the region? During 2005 - $2006 \mathrm{CHF}$ International (USAID) has developed a program and brought American experts to get things starting. Ile et Villain, GTZ etc. has carried on similar projects. No results till now; and now, the big event on, not a word on the subject.

Local business men have detected the future opportunities. Several hotels have opened or are ready to get stating next months. Former $2^{*}$ Bulevard Hotel turned into $4 *$ Continental 
Forum, Continental will be a $3 *$ Ibiss, the new $4 *$ Ramada, a $5 *$ Palace and 5 more hotels. Several pensions have opened and there are other authorizations to build some more. By September Sibiu will approach 4,000 places.

The future is MICE tourism. The first expat has come in Sibiu in Ramada. Finally the Mayor will realize that he is the only one person that can ask the hotels owners and managers to join. And Sibiu needs a DMC quickly. Almost of Romanian travel agencies are allowed to work both as tour operator and detailer. Eurohost Group, the only one tour operator, still waits the reconstruction of transport infrastructure to connect Sibiu and Romania with its other divisions: Austria, Check Republic, Hungary, Bulgaria. It has encouraged the participation to international fears as long as no offer was available on the market knowing that the clients that could not have a place might be its future one. Since 2006 Sibiu was hosted in the national stand but as a distinct presence. That has imposed a new presentation level for the whole stand. And starting 2007 the presence to international fairs was accompanied by large promoting campaigns that have boosted the impact on visitors and partners. Unfortunately, the travel agencies present to fairs have not prepared offers at nowadays standards. In fact, the main problem of Romanian tourism is the online payment and reservation. Romanian Banks have not joined the online payment international system and no hotel of Romania (except the brands) can be listed on international online reservation sites.

Sibiu 2007 has exploded the restaurants business. Some dozen of small pubs and clubs have flourished. Just to mention the main street and the two squares where 25 terraces offer near 2,000 places. During summertime, downtown is full of people. Wintertime will look different.

Since 1985 there was penury of promotion materials all over Romania. Sibiu 2007 has solved the problem: plenty of guides, maps, books, postcards and souvenirs. In order to keep a standard of quality but to avoid direct command, Sibiu 2007 Association has allowed the right to use its logo only after a prior evaluation of the products or services offered by the interested ventures.

\section{Bibliography:}

Lakatos, I - The methodology of scientific research programmes Cambridge University Press, 1995

PALMER/RAE ASSOCIATES - European Cities and Capitals of Culture, Study Prepared for the European Commission, 2004, pag 16

Greg Richards and Erik Hitters - Rotterdam Cultural Capital 2001: visitor research, ATLAS 2001 Gunn, C. A. (1994). Tourism Planning: Basics, Concepts and Cases, 3rd ed, Taylor and Francis, New York.

www.sibiu2007.ro 